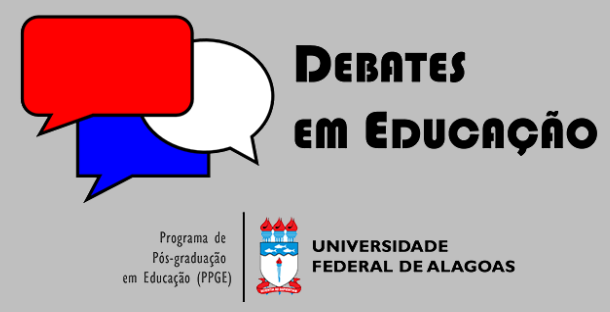

ISSN Eletrônico 2175-6600

Vol. 13 I Número Especial I 2021

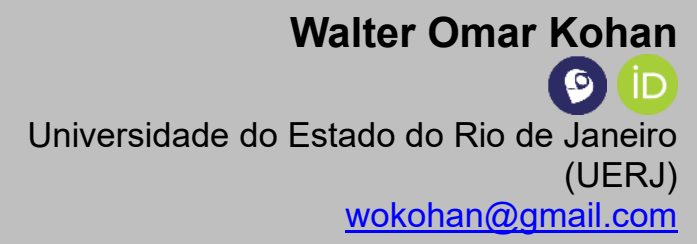

Walter Omar Kohan

\section{HÁ (UM) MÉTODO PAULO FREIRE?}

\section{RESUMO}

O presente trabalho problematiza a existência de um método Paulo Freire. Numa primeira parte apresenta antecedentes terminológicos e históricos da palavra método. A seguir oferece alguns apontamentos de Paulo Freire em relação ao método e o valor que outorgava à curiosidade e compromisso político em relação ao método. Numa seção posterior, ocupa-se das relações entre a presença ou não de um método na formação docente e na relação que o ou a docente estabelece consigo mesma. Finalmente, tece algumas considerações finais a respeito de uma pedagógica infantil (menina) da pergunta e sua relação com o método ou sua ausência.

Palavras-chave: Paulo Freire. Método. Formação de professores. Pedagogia Infantil da pergunta.

\section{IS THERE (ONE) PAULO FREIRE METHOD?}

\section{ABSTRACT:}

This article problematizes the existence of a Paulo Freire method. In the first part, it presents the terminological and historical background of the word method. Then, it offers some notes by Paulo Freire in relation to the method and the value he gave to curiosity and political commitment in relation to method. In a later section, it deals with the relationship between the presence or absence of a method in teacher education and the relationship that the teacher establishes with herself. Finally, it draws some final considerations about a child pedagogy (girl) of the question and its relationship with the presence of an absence of a method.

Keywords: Paulo Freire. Method. Teacher education. Child Pedagogy of question.

Submetido em: $05 / 04 / 2021$

Aceito em: $23 / 06 / 2021$

Publicado em: 29/09/2021

https://doi.org/10.28998/2175-6600.2021v13nEspp1-15 


\section{APRESENTAÇÃO}

Estamos vivendo uma guerra sangrenta no Brasil. Não é uma guerra recente; ao contrário, faz parte do projeto colonizador imposto há mais de cinco séculos em nossa América (ou de uma vez por todas deveríamos chamá-la Abya Yala, o nome dessas terras que antecedia à invasão europeia em vez de reproduzir o nome de um invasor?). As comunidades indígenas, negras e, em geral, as mais empobrecidas são as que dão o mais duro testemunho desta guerra. Elas também são os que resistem com mais dignidade e fortaleza.

O aspecto mais específico do atual momento brasileiro é a virulência desta guerra, seu caráter ostensivo e brutal, já que o atual governo de Jair Bolsonaro não faz nenhum esforço para esconder seu desejo de exterminação. Pelo contrário, ele faz da afirmação da morte uma autopromoção, seja na sua pulsão armamentista seja na sua criminal negação da

gravidade da pandemia para a saúde pública. É a consumação da necropolítica: "a instrumentalização generalizada da existência humana e a destruição material dos corpos e populações humanas" (MBEMBE, 2018, p. 10-11). Descrevamos, em palavras simples, inspiradas em Foucault (2006), a política atual da administração bolsonarista: um dispositivo de exercer o poder governamental para fazer morrer e não deixar viver. Esse é o dispositivo que nos governa atualmente.

Faz parte desta política um absoluto desprezo pela educação e saúde públicas, campos povoados por desigualdades que, em vez de combatê-las, esse dispositivo estimula a partir de uma lógica meritocrática e empresarial; a falta de respeito à gestão democrática em todos seus níveis; a militarização da escolarização; a absoluta carência de sensibilidade para os problemas endêmicos da educação e saúde neste país. Pelo contrário, com a pandemia, a situação tornou-se muito mais grave e preocupante devido às condições precárias do sistema público de saúde e das escolas públicas fechadas por meses e agora reabertas sem políticas de cuidado e vacinação apropriadas e sem que a população mais pobre tenha mínimas condições de conectividade e acesso.

Neste contexto, Paulo Freire ocupa uma posição curiosa, erigido em inimigo por uma administração que tem colocado até agora só economistas como ministros da educação. Já durante sua vida, Paulo Freire havia respondido aos discursos conservadores que se opunham à reconhecer a dimensão política da educação e hostilizavam qualquer pretensão 
de transformação social através da educação. Desde 2016, com a deterioração da situação política no Brasil, esta posição em relação ao seu trabalho - que sempre esteve presente tornou-se muito mais incisiva; no golpe e nas manifestações antidemocráticas contra o governo de Dilma apareceram bandeiras odiosas contra o professor pernambucano, seguidas de vozes nas redes sociais que culpavam Paulo Freire por todos os problemas da educação brasileira e o tornavam um símbolo não mais do divino, mas do diabólico.

Assim, o odiado Paulo Freire passou a ser parte do programa governamental de J. Bolsonaro pela negativa: "expurgar a ideologia de Paulo Freire da educação brasileira" que acabou sendo eleito em 2018; Paulo Freire continua sendo um inimigo explícito pelos funcionários do regime. Algumas perguntas restam em nós: como é possível que esse programa tenha sido o mais votado até mesmo pelo povo oprimido? Para além das paixões tristes e alegres despertadas pelo educador das utopias, podemos superar o discurso do ódio e considerar qual seria o valor de sua vida e de seu trabalho para pensar em nosso devastado presente educacional? Em que medida, nesse ano dos cem anos de Paulo Freire sua obra e sua vida podem nos ajudar a pensar problemas ou questões relevantes de nosso presente?

Paulo Freire é um exemplo a mais onde coincidem tantas semelhanças entre o governo atual e a ditadura de 1964: ambos pretendem expulsar Paulo Freire, idealizador de um Plano Nacional de Alfabetização, da realidade educacional brasileira. Um educador popular é considerado inimigo. Ele já não está vivo entre nós; então a expurgação ideológica ocupa o lugar da prisão e do exílio. Mas a relação é a mesma: ditaduras não gostam de educadores do povo nem de um povo letrado.

Precisamente a uma destas questões - relativa ao letramento do povo - vou me referir neste pequeno ensaio: é preciso um método para alfabetizar e de um modo mais amplo, para educar? Em outras palavras, é necessário, preciso ou conveniente que um educador ou educadora adote um método específico, predeterminado, para realizar a sua tarefa? A figura de Paulo Freire pode ser interessante para pensar essa questão por vários motivos. Como é sabido, Paulo Freire criou um método de alfabetização, conhecido como "o método Paulo Freire". Ele tem gerado muitas práticas e estudos. Há muita coisa escrita sobre esse método. Ele aparece aludido frequentemente nos ataques e nas defesas do educador de oprimidos. Contudo, a tese que defenderemos neste texto é que mesmo por razões práticas e contextuais ele tenha proposto um método, sua forma de se relacionar com esse e outros 
métodos ajuda a problematizar a ideia de método e sinaliza que cada educador deveria procurar e encontrar seu próprio método, seu próprio caminho antes que aplicar o método criado por outro, mesmo o método Paulo Freire. Há implicações políticas na exigência de que docentes adotem um certo método. Essa exigência atravessa propostas autoproclamadas democráticas ou autoritárias e são essas implicações que, esperamos, este texto ajude a repensar.

Dessa forma, se este texto tem algum valor poderia ser o de nos ajudar a pensar sobre os desdobramentos políticos que se seguem de algum caminho ou caminhos pedagógicos, e também os efeitos políticos derivados da relação que mantemos com os caminhos que seguimos quando educamos. Assim, se entendemos método no sentido amplo do caminho, a questão que Paulo Freire nos ajuda a pensar não é tanto "método sim ou método não" - já que sempre temos que caminhar por algum caminho - mas como nos relacionamos com o método/caminho e as formas de caminhar na educação e que implicações políticas essa determinação traz para o exercício docente.

\section{CONSIDERAÇÕES SOBRE O "MÉTODO"}

\subsection{A palavra 'método' e algumas tradições dominantes}

A etimologia da palavra "método" é grega: o dicionário dessa língua diz que méthodos é uma palavra composta da preposição metá (entre, depois; além) e o substantivo hodós (caminho) com o sentido de busca, procura, substituição e, derivado deles, busca de conhecimento, investigação, forma de investigar, sistema (LIDDELL; SCOTT; JAMES, 1966). $\mathrm{Na}$ modernidade europeia, um número significativo de filósofos, talvez por causa de sua proximidade com as ciências naturais, dedicou obras ao método. Um deles foi $\mathrm{F}$. Bacon que, no século XVII, publicou o Novum Organum, que poderia ser traduzido como Novo Método e que buscava um novo instrumento, mais empírico e menos especulativo para a filosofia. Talvez o mais conhecido destes trabalhos seja o Discurso sobre o Método de R. Descartes (originalmente intitulado "Discurso sobre o método para conduzir bem a razão na busca da verdade na ciência") que, para muitos, foi um marco para o que deveria ser entendido como investigação filosófica legítima, baseado em suas quatro regras: evidência, análise, ordem e enumeração (DESCARTES, 2003). Desta forma, o método foi entendido como a única 
maneira de acessar conhecimentos certos e verdadeiros; um procedimento com etapas claramente definidas e sequenciadas.

Quase todas as correntes contemporâneas da filosofia europeia, algumas das quais influenciaram fortemente Paulo Freire, questionam a imagem cartesiana do método. A filosofia Hermenêutica, por exemplo, se opõe a este valor do método científico como garantia de verdade, rejeitando sua aplicabilidade universal. Por exemplo, Hans-Georg Gadamer, em Verdade e Método, enfatiza a importância das humanidades que resistem à hegemonia do conceito cartesiano de método. A este conceito de método, Gadamer opõe a noção de Bildung, com o sentido de uma formação cultural processual. (GADAMER, 1977). Poderíamos multiplicar as referências em outras correntes de pensamento, mas talvez seja mais interessante ir diretamente ao conceito de método.

\subsection{Método: curiosidade e compromisso político}

Freire não escreveu um texto dedicado exclusivamente ao "método", embora ele se refira a ele em várias obras, especialmente desde seu primeiro período, e muitos autores próximos a ele escreveram livros sobre seu método (BRANDÃO, 1981; ver também a entrada "método" em STRECK; REDIN; ZITKOSKI, 2018). Já no exílio, coordenando o setor de Educação do Conselho Mundial de Igrejas em Genebra, Suíça, Paulo Freire realizou várias campanhas de alfabetização, particularmente em países africanos de colonização portuguesa e em alguns países latino-americanos. Por razões complexas, a aplicação do método nestas campanhas ofereceu "resultados" contrastantes; em algumas, pouco expressivos em termos quantitativos, algo que Paulo Freire nunca negou mas, pelo contrário, debateu e escreveu sobre (por exemplo, ver FREIRE 2007 [1997] e 2010 [1992]).

É bem conhecido que Paulo Freire, além de seus livros monológicos, escreveu vários livros em diálogo e deu inúmeras entrevistas. Na verdade, ele preferiu esta forma de escrita, e a seguir vamos nos ocupar de uma destas entrevistas, que se concentra precisamente na questão do método. A entrevista foi conduzida por Nilcéa Lemos Pelandré, que na época estava fazendo sua pesquisa de doutorado sobre os efeitos a longo prazo do método Paulo Freire.

Nilcéa, que é professora de Metodologia de Ensino na Universidade Federal de Santa Catarina, começa a entrevista argumentando que há muito debate sobre os aspectos 
filosóficos e políticos do método Paulo Freire, mas que ela preferiria se concentrar nos efeitos do método sobre os níveis de leitura e escrita daqueles que foram ensinados a ler e escrever por ele. Porém, apesar de seus esforços, a entrevista concentra-se mais no que mais interessa a Freire: precisamente os aspectos filosófico-políticos do método, que ela mesma abre com sua primeira pergunta sobre os princípios cardeais do método, em termos filosóficos, políticos e pragmáticos. Devido à sua importância, transcreverei a primeira parte da longa resposta de Paulo Freire:

\begin{abstract}
Eu começaria a responder sua pergunta fazendo umas considerações que me parecem, do ponto de vista epistemológico, importantes. Considerações em torno da expressão que você usou, e que não é só você que usa, todos usam, quando me perguntou sobre 'o método'. Eu preferiria dizer que não tenho método. O que eu tinha, quando muito jovem, há 30 anos ou 40 anos, não importa o tempo, era a curiosidade de um lado e o compromisso político do outro, em face dos renegados, dos negados, dos proibidos de ler a palavra, relendo o mundo. O que eu tentei fazer, e continuo fazendo hoje, foi ter uma compreensão que eu chamaria de crítica ou de dialética da prática educativa, dentro da qual, necessariamente, há uma certa metodologia, um certo método. (PELANDRÉ, 2014, p. 14)
\end{abstract}

Vale a pena prestar atenção a cada detalhe da resposta. Em primeiro lugar, Paulo Freire assinala que ele precisa fazer considerações importantes do ponto de vista epistemológico: "Eu preferiria dizer que não tenho método". E então justifica e dá outros nomes ao que se chamou de método em sua juventude: a curiosidade e o compromisso político. Estes são conceitos importantes que estão situados em lugares diferentes do processo educativo em relação ao método. Se o método está presente mais no meio do processo, no interior dele, a curiosidade está mais fortemente implicada no início e o compromisso político guia a viagem educacional desde o final, como um horizonte. Se o método tem a ver com a forma como educamos, a curiosidade fala da razão ou motivo pela qual educamos e o compromisso político se refere ao sentido ou para quê o fazemos. Se a curiosidade é um princípio do qual partimos e que nos impulsiona a andar, o método é uma forma de transitar, andar, e o compromisso político alude ao significado de educar.

Assim Paulo Freire deixa muito claro que sua principal preocupação sempre foi com questões de princípios e sentidos de educar, muito mais do que com questões de caminhos, métodos ou metodologias. É claro que ele tinha um método no sentido de que era necessário caminhar de alguma forma, mas - e este esclarecimento também é muito significativo - era mais um método de saber (epistemológico) do que de ensinar (pedagógico). Por que este esclarecimento é importante? Porque mostra que para Paulo Freire, se era necessário 
antecipar um determinado caminho ou forma de saber, ele não era necessário por razões pedagógicas, para ensinar, mas por razões epistemológicas, já que era uma forma de produzir conhecimento: o método era mais epistemológico do que pedagógico.

Vamos deter-nos um pouco mais nessas duas coisas que Paulo Freire afirmou ter quando era jovem: curiosidade e compromisso político. $E$ antes de entrarmos nelas, notaremos um detalhe: "não importa o tempo". Paulo Freire parece querer nos alertar para o fato de que esta questão, situado em sua juventude, vai além dos tempos; que, na verdade, ele a levanta em relação à sua juventude porque está sendo questionado sobre aquele tempo, o tempo de suas campanhas de alfabetização; mas na realidade é uma questão que está relacionada a qualquer tempo no campo da alfabetização, e não apenas ao tempo de suas campanhas de alfabetização.

Vejamos então esses dois componentes do "jovem" Freire: curiosidade e compromisso político. A primeira é uma condição para que educadores e educadoras de todas as idades eduquem pessoas de qualquer idade. Freire o diz da maneira mais diversa possível, em seus textos, em suas Cartas a Cristina (FREIRE, 2008 [1994]) e a Nathercia (LACERDA, 2016), em sua vida. Talvez no livro falado com Antonio Faundez, Por uma pedagogia da pergunta, é onde ele o faz da forma mais explícita e claramente: educar significa, sobretudo, alimentar a curiosidade que está na base de cada pergunta, por isso é necessária uma pedagogia da pergunta e não da resposta (FREIRE; FAUNDEZ, 2013 [1985]). Sem curiosidade não há conhecimento, não há educação, nada que valha a pena. Também neste texto, a curiosidade precisa ser cuidada e nutrida e está associada ao modo de vida de uma menina. É por isso que a infância ou meninice, entendida como uma possibilidade de existência e não como uma etapa da vida, é antes algo que educa e não algo a ser educado, como temos argumentado amplamente em outros lugares (KOHAN, 2019; 2020). Uma vida educadora cuida para manter viva essa curiosidade e inquietação infantil, a fim de educar pessoas de todas as idades.

Por outro lado, o compromisso político com os "renegados, negados, proibidos de ler a palavra, relendo o mundo" é outro componente insubstituível e não negociável dos educadores de todas as idades. É a educação como política: uma política que não é definida por um dogma particular, mas por um estar junto a um sujeito político caracterizado por sua negação. É uma posição política ao educar. Há um sujeito político que foi roubado de sua condição existencial e política; um sujeito que não pode ser quem é, que é impedido de 
realizar sua vocação para conhecer e ser mais. Portanto, qualquer prática educacional que mereça este nome precisa se colocar como sentido que esse sujeito impedido, oprimido e negado pode se tornar quem ele ou ela é.

Paulo Freire deu nomes diferentes a este compromisso. Mesmo nas linhas que seguem o parágrafo transcrito, ele esclarece: "Prefiro me entender como um homem curioso e pesquisador de uma certa concepção democrática, radical e progressiva da prática educacional". Ou seja, que o compromisso político com os negados é aqui chamado de concepção democrática, radical e progressista da prática educacional. Não estamos tão preocupados agora com estas nuances. O que importa é perceber que a questão do método específico para educar é secundária à curiosidade e ao compromisso político que move uma prática educacional, aos princípios e sentidos que inspiram esse caminho.

\subsection{Formação: tornando-se o método que somos}

$\mathrm{Na}$ continuação dessa mesma primeira resposta na entrevista, Freire desenvolve um pouco mais estas afirmações, alterando ligeiramente a apresentação. Ele oferece três fundamentos da prática educacional: a) toda prática educacional é política; b) toda prática educacional é projetada fora de si mesma para um amanhã aberto e problemático; c) toda prática educacional é cognitiva, ou seja, um processo de conhecimento composto de assuntos igualmente legítimos, trate-se de educadores ou aprendizes. E então ele sugere transferir esta análise para a alfabetização, para o qual ele faz uma distinção entre gramática e linguagem: a gramática, suas regras, é a única coisa que pode ser ensinada; a linguagem, por outro lado, é aprendida socialmente; portanto, a alfabetização é um ato criativo e, estritamente falando, ninguém ensina ninguém a ler e escrever. É por isso que não pode haver nenhum método para alfabetizar.

Que não exista antecipadamente um método não significa que o alfabetizador ou alfabetizadora não precise saber algumas das coisas necessárias para uma passagem tranquila por este caminho: por exemplo, que para alfabetizar é necessário partir da linguagem cotidiana dos alfabetizandos e alfabetizandas, resultado de uma leitura do mundo que precede a leitura da palavra; que a proximidade cultural entre alfabetizador(a) e alfabetizando(a) facilita o processo; que o reconhecimento do conhecimento dos-as alfabetizandos(as) o(a)s encoraja a olhar mais além; também não significa que não existam 
requisitos linguísticos, nem limitações fonéticas para o processo de alfabetização. Finalmente, a ausência de um método também não significa que não existam técnicas que possam auxiliar neste processo. O que Paulo Freire quer significar é que nenhuma técnica pode ser auto-contida ou considerada aplicável a qualquer contexto ou imutável, e que cada educador(a) / alfabetizador(a) precisa se relacionar criativamente com qualquer técnica que ele ou ela opte por praticar.

Outro aspecto que Paulo Freire considera importante tornar explícito é a formação de alfabetizadores e alfabetizadoras. Ele é muito claro a este respeito: "a formação contínua se baseia na reflexão sobre a prática. É pensando criticamente na prática que se destila desta prática a teoria que já se conhece ou não" (p. 20); em outras palavras, a formação precisa ser mais política e filosófica do que metodológica ou técnica.

Quando Nircéa perguntou a Paulo Freire se as orientações eram as mesmas nos diferentes países onde o método era aplicado, Paulo Freire foi muito claro: "É pensando criticamente a prática que você desembute dessa prática a teoria que você já conhecia ou não.". Mais uma vez: a formação é filosófica, trata-se de pensar criticamente sobre a prática e voltar sempre mais da prática para a teoria e da teoria para a prática.

Se até este ponto Paulo Freire tem sido muito claro sobre a subordinação do método à sua dimensão política e filosófica, torna-se ainda mais claro quando Nircéa pergunta se ele aplicou sua teoria em sua administração como Secretário de Educação da cidade de São Paulo. Por causa da importância da resposta, transcrevo, abaixo, uma parte dela:

Nós trabalhamos seguindo muita gente, não necessariamente Paulo Freire. Dizíamos sempre que não havia necessidade de seguir Paulo Freire, nem João, nem ninguém. A exigência é que fosse aplicada uma pedagogia progressista. O que importava era saber se o educador tinha uma cultura dialógica e aberta, respeitosa com o povo. No fundo, cada educador é um método. Não tem que estar bitolando.

Vamos prestar muita atenção. Na primeira parte de sua resposta, Paulo Freire tinha apresentado o Movimento de Educação de Adultos (MOVA) de São Paulo, criado durante sua administração, e também tinha falado de suas parcerias com os movimentos populares dos subúrbios de São Paulo. Ele também tinha mencionado como a administração sucessiva e reacionária de Paulo Maluf colocou um fim a todo este trabalho político. Em seguida, ele passou a se referir afirmativamente à sua administração. Mais uma vez, Paulo Freire não fala de métodos ou técnicas: ele afirma que as orientações para as práticas educacionais eram 
plurais durante sua administração e que a exigência era que os educadores e educadoras aplicassem uma pedagogia progressista, palavra que ele já havia utilizado no início da entrevista para se referir ao significado político da prática educacional, como democrático e radical. E ele explicita sua compreensão desta exigência a partir de considerações epistemológicas, filosóficas e políticas: uma cultura de diálogo e abertura, de respeito ao povo. Então, Paulo Freire termina sua resposta com uma declaração extraordinária: "No final, cada educador é um método", seguido de um esclarecimento: "não tem que estar bitolando".

Paulo Freire parece querer passar de um extremo para o outro. Diante das culturas autoritárias, presentes inclusive no meio educacional; perante a rigidez daqueles que aplicam receitas rígidas, unificadoras e totalizadoras, ele exige uma maleabilidade metodológica em termos de coerência política, filosófica e epistemológica de uma prática pedagógica. O que importa no ato educativo está muito mais nestas dimensões que na unidade metodológica.

Entretanto, há algo mais: "Cada educador é um método". Isto significa que não podemos separar quem alfabetiza de como alfabetiza porque cada pessoa alfabetizadora se faz e se encontra na forma que encontra para afirmar seu compromisso epistemológico, filosófico e político numa educação emancipatória. Não há como separar o método de alfabetização da pessoa alfabetizadora. Além disso, não há nenhum método de alfabetização fora de uma existência alfabetizadora. "Cada educador é um método". É por isso que a tarefa de encontrar o próprio caminho é insubstituível para aqueles e aquelas que dedicam suas vidas à educação popular, porque nessa forma, que só cabe em quem a encontrou a partir de um processo dialógico e reflexivo estará refletida a especificidade com que essa vida educadora busca realizar seu compromisso epistemológico, filosófico e político com a educação popular.

"Cada educador é um método". Toda vez que afirmamos algo, não afirmamos outras coisas. Vejamos o que esta frase não afirma, o que ela poderia ter afirmado sobre a relação entre cada educador(a) e o método que Paulo Freire preferiu não afirmar, entre tantos outros possíveis. Primeiro, a questão do gênero que, sabemos, era sensível a Paulo Freire e também por isso estamos explicitando em nosso texto, mesmo que trave ou torne mais emaranhada a sua leitura. Segundo, Paulo Freire poderia ter afirmado algo oposto e mais radical: "Cada educador (ou educadora) não é um método". Em certo sentido, são frases opostas: a primeira identifica cada educador (e educadora) com um método; a segunda nega esta identificação. Entretanto, em outro sentido, ao lê-las, as frases tornam-se mais próximas 
se o "um" tem o sentido de numeral, unidade: ao identificar cada educador com um método, o método se multiplica para cada educador, e assim cada educador não é um método único. Finalmente, vejamos outras variantes de verbos que Paulo Freire poderia ter usado no lugar do verbo ser: "Cada educador tem (aplica, procura, encontra, assume, busca, descobre, inventa, cria, concebe, traça, esboça, delineia, projeta) um (seu) método". Nenhuma dessas frases seria necessariamente falsa para Paulo Freire. Pelo contrário, talvez o educador pernambucano considerasse todas elas como verdadeiras ou com sentidos interessantes. Cada uma delas enfatiza uma dimensão diferente na relação de cada educador(a) com um método.

Contudo, nenhum verbo, como o verbo "ser", mostra a impossibilidade de separar o método de seu executor: não há nenhum método fora de uma existência que o cubra com significados epistemológicos, filosóficos e políticos; o método está na dimensão ontológica do ser educador ou educadora. Mesmo assim, talvez exista um verbo que, imaginamos, seja ainda mais consistente e atento a essa dimensão democraticamente aberta e errante na relação de cada educador e educadora com seu método. Por isso, se tivermos que reescrever essa frase diríamos: "cada educador e educadora está um método". Dessa forma estaríamos indicando uma relação menos fixa e mais aberta às trajetórias dessas vidas educadoras na sua relação com um método.

\section{CONSIDERAÇÕES FINAIS ANTIMETÓDICAS}

Como durante toda sua vida, mesmo mais de 20 anos após sua morte, Paulo Freire continua a dividir águas. Estamos nos aproximando do $100^{\circ}$ aniversário de seu nascimento e as águas estão se tornando cada vez mais agitadas e turbulentas. O mesmo sucede com seu "método": estão aqueles que o deificam e aqueles que o defenestram. Aqueles que o consideram milagroso (com o método Paulo Freire seria logo resolvido o analfabetismo no Brasil) e aqueles que o acham errado e perigoso e, portanto, deveria ser expurgado da educação brasileira. Neste breve ensaio, tentamos tomar outro caminho: olhar para Paulo Freire como um companheiro a fim de problematizar a forma como a questão do método pode ser pensada neste momento; não tanto para entender seu método e defendê-lo ou condená-lo, mas para pensar como ele pode nos inspirar a levantar algumas perguntas sobre a forma como cada educador se relaciona ou poderia se relacionar com sua própria forma de 
viver uma vida educadora. Os leitores e as leitoras deste texto poderão dizer acerca da força ou da fraqueza deste exercício para pensar sua própria relação com o método.

Descobrimos uma inspiração: "cada educador é um método". O verbo "ser" pode ter o valor de uma identidade, uma qualidade, uma possibilidade, uma dimensão, uma contingência, um risco, uma aposta, uma ousadia. E tantas outras coisas. Sugerimos uma leve nuance: "Cada educador ou educadora está um método". O novo verbo indicaria uma relação mais provisória, mutável, livre? com o método. Em qualquer caso, a frase também mostra uma inseparabilidade e uma condição: não há método fora de quem o coloca em prática: mais do que isso, na educação popular, talvez praticar um método signifique todas essas coisas juntas: (re)criá-lo, inventá-lo, vivê-lo, ser ele, estar ele. E mais algumas que deixo as leitoras e leitoras imaginar. Neste sentido, devido à inseparabilidade entre o método e seu praticante, inventar um método faz parte da invenção de si como educador ou educadora: inventar um método faz parte da tarefa artística de educar, parte de inventar a si mesmo(a) educador(a). Não há método (invenção de) sem invenção de si.

Estas considerações, filosóficas e políticas, que podem parecer abstratas e descontextualizadas, podem nos ajudar a pensar sobre nossas práticas educacionais nestes tempos de tanta hostilidade e precariedade nas condições do trabalho pedagógico. Destas afirmações, pode-se deduzir como consequência que a ânsia contemporânea por métodos pré-determinados, eficientes e bem objetivos que nos ajudem a empreender nosso caminho educacional, bem como a obsessão por avaliações padronizadas para medir nosso trabalho pedagógico pode ser uma forma de nos desviar de uma dimensão insubstituível em uma vida educativa: a tarefa artística de encontrar nossa própria forma de educar. Questionar esta urgência e a necessidade de encontrar um método seguro também pode nos ajudar a pensar no que colocamos de lado quando o fazemos, e também nos princípios e sentidos que damos à nossa tarefa: é possível que um método possa nos garantir bons "resultados" mas, ao mesmo tempo, ferir algo da curiosidade que sustenta nossa busca? O que estamos ensinando além das coisas que acreditamos ensinar quando nos mostramos seguindo um caminho já determinado por outros e não estando em busca de nosso próprio caminho? Que política cognitiva afirmamos e abrimos no espaço educacional disponível quando aplicamos uma estratégia metodológica definida de antemão?

A questão do método nos leva a perguntar "como?": "como explicar este programa?", "como alfabetizar esta pessoa incapaz de aprender ou ler alguma coisa?", "como fazer com 
que tal pessoa saiba tal coisa"? "Como fazer...?" As exigências de um sistema educacional, com suas exigências de planejar, objetivar, medir, avaliar, reforçam nossa preocupação com os "como...".

Ao mesmo tempo, esta exigência talvez nos faça perder de vista outras perguntas, aquelas que começam com "por quê?": "por que pressupomos que alguém é incapaz de aprender e não pensamos que talvez sejamos nós incapazes de ensinar?", "por que prestamos atenção ao que atendemos em nossa prática?", "por que estamos tão obcecados com a busca de um método?", "por que nos perguntamos o que perguntamos?", "por que não nos perguntamos o que não nos perguntamos?". E também perguntas pelo "para quê?": "para que alfabetizar?", "para que medir e avaliar tanto em vez de escutar e atentar?", "para que dedicar uma vida inteira à educação?" ... Estou dando apenas alguns exemplos de perguntas. Não há perguntas que sejam em si mesmas necessárias ou indispensáveis e outras que sejam descartáveis ou superficiais; adequadas ou inadequadas; importantes ou banais. Mas pode ser significativo considerar quais perguntas poderiam ser mais sensíveis e coerentes com nossos compromissos e significados filosóficos e políticos para acompanhar as nossas práticas educadoras.

Perceber os princípios e sentidos que Paulo Freire afirma para a educação popular no lugar do método pode nos ajudar a rever as questões que somos encorajados a expressar e pensar cotidianamente; por exemplo, prestar atenção às questões de "por quê?" e "para quê?" que são tão frequentemente deslocadas ou consideradas inúteis diante da urgência das questões de "como". Basicamente, é uma questão de nos perguntarmos o que precisamos nos perguntar a nós mesmos, porque assim como cada educador ou educadora é ou está sendo seu método, cada educador ou educadora é ou está sendo também as suas perguntas, as perguntas que se atreve a viver, em seu corpo, em seus sonhos, em sua vida educativa.

Dessa forma, em última análise, a questão do método esteja relacionada a uma pedagogia (infantil ou menina) da pergunta. Deixemos isso claro imediatamente: a pedagogia (infantil ou menina) da pergunta não é um método. Ela sugere princípios e sentidos para educar e posiciona a educadora ou educador como alguém que está permanente e infantilmente perguntando-se pelos sentidos de sua prática.

Chegou a hora de terminar. Nada melhor do que terminar com perguntas. Porque se as perguntas são uma infância para o pensamento, uma espécie de convite para o 
pensamento nascer, terminar com perguntas significa que estamos terminando por começar, que estamos fazendo do fim um começo, um convite, um novo começo. Ajudamos a pensar, com Paulo Freire, sobre o método? Ou ajudamos a pensar, com o método, sobre Paulo Freire? Ou ajudamos a pensar sobre nós mesmos? Ou ajudamo-nos a pensarmo-nos nós mesmos? As perguntas continuam surgindo: "Afirmamos um método?", "recriamos uma pergunta?", "temos ou não temos sido um método?", "o estamos sendo?" "temos ou não sido uma pergunta?", "temos (re)inventado a nós mesmos?", "honramos uma pedagogia (infantil ou menina) da pergunta?". Quem sabe, uma pedagogia menina da pergunta tenha algumas qualidades contagiantes.

\section{REFERÊNCIAS}

BRANDÃO, Carlos Rodrigues. O que é o método Paulo Freire. São Paulo: Brasiliense, 1981.

DESCARTES, René. Discurso del método; estudio preliminar, traducción y notas de E. Bello Reguera. Madrid: Tecnos, 2003.

FOUCAULT, Michel. Em defesa da sociedade. São Paulo: Martins Fontes, 2006.

FREIRE, A M. A. Paulo Freire. Uma história de vida. Indaiatuba: Villa das Letras; 2. ed. São Paulo: Paz e Terra, 2017.

FREIRE, Paulo. Cartas a Cristina. Reflexiones sobre mi vida y mi trabajo. México: Siglo XXI, 2008 [1994].

FREIRE, Paulo. Cartas a Guinea-Bissau. Apuntes de una experiencia pedagógica en proceso. México: Siglo XXI, 2007 [1977].

FREIRE, Paulo. Educación como práctica de la libertad. Buenos Aires: Siglo XXI, 2015 [1967].

FREIRE, Paulo. Pedagogía de la Esperanza. Un reencuentro con la Pedagogía del Oprimido. Buenos Aires: Siglo XXI, 2010 [1992].

FREIRE, Paulo; FAUNDEZ, Antonio Por una pedagogía de la pregunta. Crítica a una educación basada en respuestas a preguntas inexistentes. Buenos Aires: Siglo XXI, 2013 [1985].

GADAMER, Hans-Georg. Verdad y método. Fundamentos de una hermenéutica filosófica. Salamanca: Sígueme, 1977. 
GADOTTI, Moacir; TORRES, Carlos Alberto. Paulo Freire: una biobibliografía. México: Siglo XXI., 2001.

KOHAN, Walter. Paulo Freire e a (sua) infância educadora. In: SILVA, Marta Regina Paulo de; MASON, Jason Ferreira (orgs.) Paulo Freire e a educação das crianças. São Paulo: BT Acadêmica, 2020, p. 83-100.

KOHAN, Walter. Paulo Freire mais do que nunca. Belo Horizonte: Vestígio, 2019.

LACERDA, Nathercia. A casa e o mundo lá fora: cartas de Paulo Freire para Nathercinha. Rio de Janeiro: Zit, 2016.

LIDDELL, Henry George; SCOTT, Robert; JAMES, Henry Stuart. A Greek English Lexicon. Oxford: Clarendon Press, 1966.

MBEMBE, Achille. Necropolítica: biopoder, soberania, estado de exceção, política da morte. São Paulo, n-1 edições, 2018.

PELANDRÉ, Nilcéa Lemos . Entrevista com Paulo Freire, EJA EM DEBATE, Florianópolis, a. 3, n. 4, p. 13-27, jul. 2014. Entrevista publicada inicialmente em: PELANDRÉ, N. L. Ensinar e Aprender com Paulo Freire: 40 horas 40 anos depois. 3. ed. rev. Florianópolis: Editora da UFSC, 2009.

STRECK, Danilo Romeu; REDIN, Euclides; ZITKOSKI, Jaime José (Orgs.). Dicionário Paulo Freire. Belo Horizonte: Autêntica, 2008. 